\title{
Electroencephalography (EEG) analysis on human reflection towards relaxation of mind
}

\author{
Nurasma Jalaudin*, Muhamad Kamal Mohammed Amin \\ Bio Cognition Laboratory, Bio-Inspired System and Technology iKohza (Research Group), Malaysia - Japan International Institute of Technology \\ (MJIIT), University Teknologi Malaysia (UTM) 54100 Kuala Lumpur, Malaysia
}

* Corresponding author: nurasma434@gmail.com

\section{Article history}

Received 27 February 2018

Revised 28 March 2018

Accepted 21 May 2018

Published Online 14 April 2019

\begin{abstract}
This paper presents an interdisciplinary studies of electronic systems: engineering, psychology and neuro-cognition. It evaluates the neurophysiological activities of human emotion using electroencephalography (EEG). This study is aimed to classify a comparison of Electroencephalogram (EEG) signal to observe human reflection towards relaxation state of mind during divine Quran recitation and listening to music. The objectives of this study is to measure the changes in alpha band and prove that the brain is less active when the subject is listening to Quran compared to music. Six healthy subjects were recruited to measure their behaviors of the mind for a total duration of three minutes. We have highlighted the observation in Topographic Map of the brain through ERP Analysis to observe whether the brain experience any changes. The results showed that the brain activity is less active and the Alpha Power is higher when the subject is listening to Quran Recitation. We conclude that listening to Quran Recitation is a useful tool for a healthy and happy mind which can help people recognize the need of Islamic practice in human life.
\end{abstract}

Keywords: Human emotion, EEG, alpha waves

(C) 2019 Penerbit UTM Press. All rights reserved

\section{INTRODUCTION}

Human brain is constantly known as the most composite system in the universe. The waves were first tested in 1924 by Hans Berger. Different advancements are being introduced to record brain waves, but electroencephalography (EEG) has turned out to be a standout amongst the most valuable devices to analyze brain activities (Johnson, 1998).
The EEG works as a brain signal processing technique that allows gaining the selective information of the composite inner mechanisms of the brain. The waveforms recorded are intellection reasoning to reflect the activity from the brain structures underneath the cortex which is practically symmetric in an external frame, with left and right hemispheres (Kahn, 2015). The brain is separated into four segments as appeared in Fig 1.

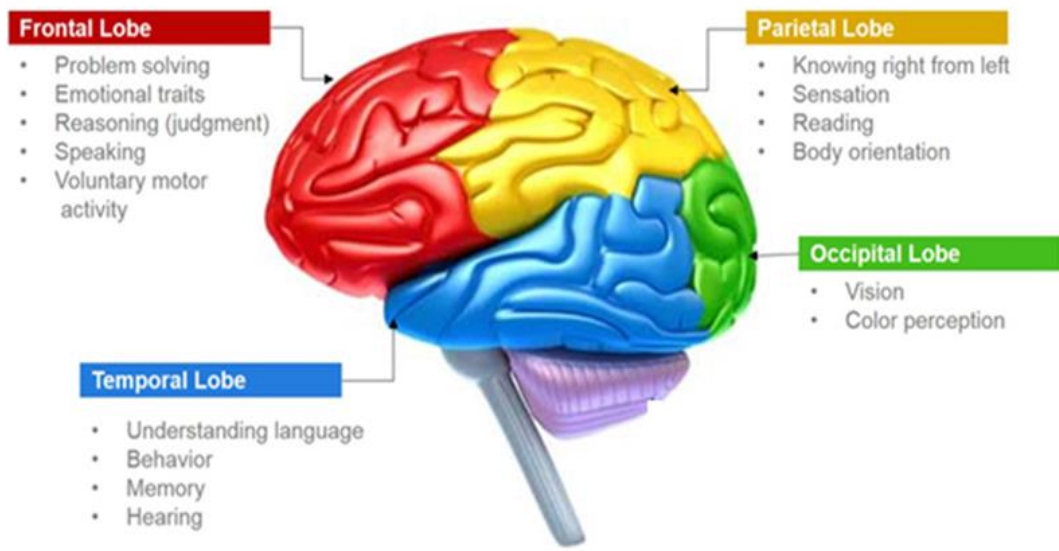

Fig. 1 Parts of the human brain. 
The frontal lobe is the piece of the mind that controls imperative subjective abilities in people, for example, passionate articulation, memory, judgment, speech and critical thinking. It is, fundamentally, the "control board" of our identity and our capacity to convey various thoughts (Abdullah \& Omar, 2011). The temporal lobe generally rotates around hearing and particular tuning in. It gets material information, for instance, sounds and speech from the ears. It is in a like manner, the key to having the ability to understand, or grasp noteworthy talk.

As for the occipital lobe, it has the ability to effectively process the fast data that our eyes are seeing. And the parietal lobe has some particular capacities. As a piece of the cortex, it has a ton of duties and must have the capacity to process tangible data immediately. People would not have the capacity to feel impressions of touch if the parietal lobe was harmed. Harm to the parietal lobe can prompt issues with verbal memory, a disabled power oversight, and in addition issues with dialect (Shekha et al., 2013).

The Brain is comprised of billions of brain cells called neurons. Neurons act like an electrical switch, either it is in an OFF state as the body is resting, or it is in an $\mathrm{ON}$ state and shooting an electrical impulse down the axons. At the very end of the axons, chemicals are spit out to trigger another neuron to send a message. This is why neurons are known as an electrically excitable cell that processes and transmits information by electrochemical signal with other cells called synapses (SpringerLink \& Zhang, 2012). Distinctive neurons utilize diverse sorts of chemicals, and these chemicals are called as transmitters.

Hence, the most suitable device to measure the electrical activity of the brain is electroencephalograph (EEG). The study of continuous EEG signal wave is perplexing, because of the huge measure of data obtained from each electrode (Amin et al., 2014). The EEG is normally depicted as far as rhythmic activity. The rhythmic activity action is separated into groups by recurrence. EEG recurrence groups are regularly arranged into four classifications, for example, alpha, beta, delta and theta. Alpha wave is the one concerned about unwinding and the resting state, and this type of band (Alpha Band) has been the main focus of this study (Azizi, 2009). Fig. 2 represents the external simulation of brain states.

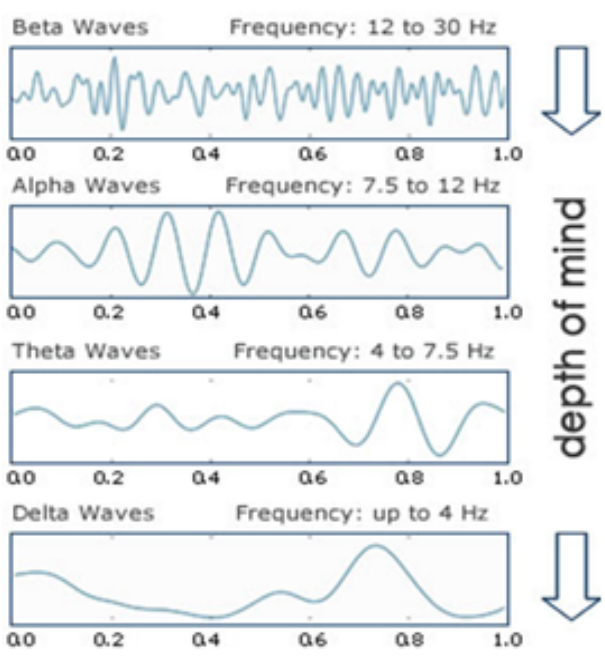

Fig. 2. Various EEG wave patterns.

This study aims to analyze the human reflection towards relaxation of mind via electroencephalography and discover the impacts on the temporal lobe of the brain while tuning in to music and Quran recitation. Alpha waves are one kind of brain waves distinguished by electroencephalography (EEG) and transcendently start from the occipital lobe amid alert unwinding with closed eyes.

Beta waves fluctuate inside the scope of $13 \mathrm{~Hz}$ to $30 \mathrm{~Hz}$. Beta waves are the standard waking mood of the brain related to dynamic considerations, expectations, or taking care of solid issues. It is ordinarily found in grown-ups. Rhythmic beta activity is essentially experienced over the frontal and central region. The amplitude is regularly under $30 \mu \mathrm{V}$ and under $20 \mu \mathrm{Vpp}$ (Cahn \& Polich, 2006). Specifically, it is tried to relate to the EEG signal frequencies with human emotions when the subject is instructed to listen to music and Quran recitation. Although both methods (Quran recitation and music) are claimed to generate alpha activities which indicates that the subject is relaxed, there must be some differences between them that we can identify. This paper aspires to prove that Quran recitation can lead someone to relaxation and serenity.

\section{LITERATURE REVIEW}

\section{Electroencephalogram (EEG) and Event-Related Potentials (ERP)}

Evaluation of brain signals, through electroencephalogram (EEG) and event-related potentials (ERPs), has become a broadly utilized strategy, in absolute terms of access code, to equipment, and ease of acquisition. Technically, EEG and ERP measures are highly preferred not only to clinicians, but to anyone trying to understand the mechanism principal of everyday behavior, cognition as well as emotion (Chen \& Zhao, 2008) .

The electrical activity of the brain can be recorded and interpreted by using Electroencephalography (EEG) technique. A number of pairs of electrodes are attached to the scalp to record the electrical activity of the brain since the brain use electrical signals to communicate with other neurons (Davidson et al., 2002). The combination of these signals by millions of neurons will create a colossal measure of the brain activity. 


\section{EEG acquisition}

EEG signaling acquirement in biomedical designing is very significant for signal psychoanalysis. EEG is a standout amongst the most essential devices in recognizing the condition awareness of a person. The EEG sensor net usually comes with 32, 64, 128, and 256 channels of electrodes. In this research, we are going to use a sensor net with 256 channels of electrodes. The advantage of using a large number of electrodes is that it can give us a very precise reading. Furthermore, it can also improve the spatial resolution (Gilman, 2015). This layout represents the layout of the human brain and each electrode position, according to 10-10 systems, equivalent to HydroCel GSN which represents the lobe of the brain.

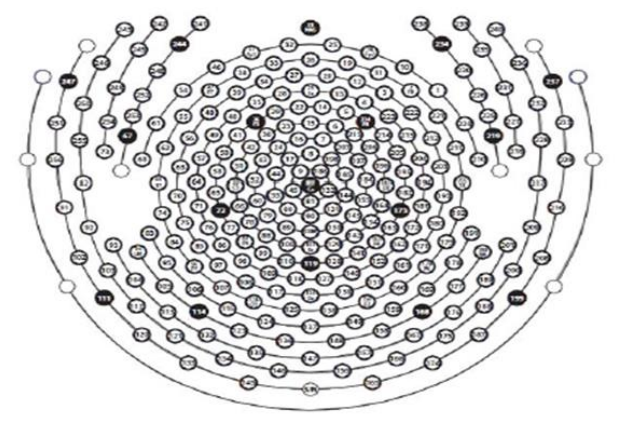

Fig. 3 Layout illustrating the approximate $10-10$ equivalent on the 256-channel HydroCel GSN.

\section{A study of the effect of sound on EEG}

Listening to music assumes an essential part of higher mind focuses (De la Torre-Gea \& García-Manzo, 2016). With respect to music, mind pliancy likely happens in various stages. The tonal courses of action in vocal and instrumental music (interval, melody, and harmony) produce physiologically intelligent motions in the sensory system that is maybe natural and developmental in nature, helping the creature to remember the maternal children's song of earliest stages and the coupling call of warblers, in this manner catching the audience/player's attention. Listening, playing, and practicing music enact chosen groups of neurons and their associated areas monotonously in the way of procurement of learning and development of memory (Boutros \& SpringerLink, 2013). The learning-related changes in the brain are additionally fortified by the feeling actuating impacts of music. This property of music is maybe because of the game plan of melodic notes in a various leveled structure that in some ways are parallel to the anatomical design of the sensory system (Key \& Crowley, 2012).

Davidson et al. (1988) recommended that the left frontal range is engaged with the experience of positive feelings, for example, satisfaction and joy. Interestingly, the correct frontal locale is engaged with the experience of negative feelings, for example, dread, outrage and misery. Utilizing EEG estimations, Davidson et al. (1990) discovered significant confirmation for the hilter kilter frontal mind enactment. From that point forward, few EEG practitioners think about utilizing different arrangements of melodic boosts to help the hemispheric specialization speculation for enthusiastic valence. That is, melodic boosts which are viewed as positive or negative in valence, evoked unbalanced frontal EEG movement (McDermott, 2012).

Schmidt and Trainor (2001), for instance, researched examples of EEG movement incited by melodic extracts in a gathering of stuents. They discovered more noteworthy left-and right frontal movement amid music tuning in to charming and repulsive music. Sammler et al. (2007) examined electrophysiological connects amid the handling of lovely (consonant) and offensive (noisy) music utilizing both heart rate and EEG estimations. In the EEG they found an expansion of frontal midline theta control for lovely music rather than disagreeable music (Trainor, 2008).

Human feeling and its association with cerebrum movement in EEG are still very much incomplete. It is frequently noticed that view of music and subsidiary feelings are exceptionally culture-bound. As perplexing feelings, portrayal of music emotions goes past the great excitement, hedonic, and predominance measurements. This examination was performed to assess the impact of fleeting EEG signals while tuning in to Quran recitation. With a specific end goal to fortify the discoveries, music was contrasted with the Quran recitation.

\section{METHODOLOGY/MATERIALS}

Five Muslims and a non-Muslim aged from 20-24 years old, both male and female, participated in the experiment. All of them are healthy and free from any disease and medication. All participants are given verbal consent regarding the experiment protocol. The flowchart in Fig. 4 shows a short explanation of the process in determination of auditory stimuli on EEG.

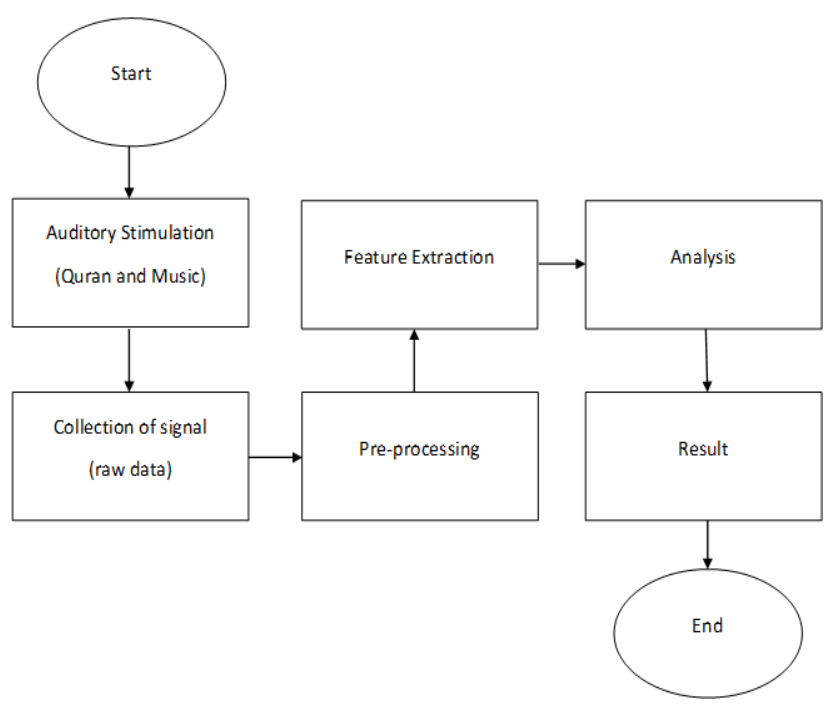

Fig.4 process in determination of auditory stimuli on EEG signal.

\section{DATA COLLECTION}

For data collection, the subjects were asked to sit comfortably. Then the subjects were instructed to rest and listen to music and Quran recitation for three minutes using headphones with their eyes closed. Each session was divided into three parts: before, during, and after listening to both. The subjects were asked to take a few minutes rest at the end of each session before proceeding to the next session. After that, the data was recorded through pre-processing to get EEG signal. The data was then extracted to get the features before being analyzed by using Matlab software.

\section{Hardware}

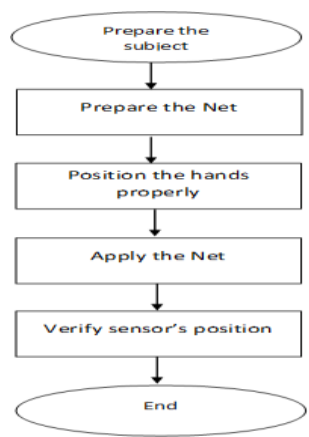

Fig. 5 Flowchart of applying the sensor Net on subject's head.

In this experiment, there are several steps needed to be taken throughout the experiment. First thing is to prepare the subject. During this time, the measurement of the subject's head circumference is measured, starting from the brow bone to $2.5 \mathrm{~cm}$ ( 1 in.) above the inion, back to the brow bone. This measurement is important in order to determine the size of the Net (Kahn, 2015). The Net comes with three 
different sizes. The $\mathrm{CZ}$ position of the vertex is also measured and marked. Then the Net's sensor end is soaked in electrolyte solutions for five minutes. The hands should be properly positioned underneath the face straps. Then, the net is applied on the subject's head. The CZ position or Cortex position must be placed on the marked position as measured during the first step. Only then can the Net be adjusted using the ear and eye band beads so that they do not rest on the jaw bone. The placement of the vertex, nasion and mastoid sensors are checked. Each sensor was briskly scrubbed side to side on the scalp to ensure good contact with the scalp.

\section{Software}

In this project, three types of software are used in acquiring and analyzing the data:

\section{E-prime version 2.0:}

E-prime is the extension to EEG acquiring system. This software is used to control the experiment. Particularly, how we want to design the experiment.

\section{Net Station 5:}

Net Station Acquisition runs as an acquiring system of EEG data.

\section{MATLAB:}

The purpose of using MATLAB is to obtain Power Spectral Density (PSD) of alpha brainwaves power. The file from Net Station is Converted to a .mat file by using Exporting tool in Net Station Tools. The .wmv file is converted into 3D array, creating a segmented file of "Music" and "Quran" in MATLAB matrix workspace.

\section{RESULTS AND FINDINGS}

The results were analyzed from 256 channels of electrodes. EEG data of auditory listening task was divided into two segments namely Quran and Music. These segments are recorded as "Good" after the preextraction process of the raw data has been completed as shown in the fig. 6 below. The alpha brainwaves $(8-13 \mathrm{~Hz})$ are produced.

\section{ERP analysis}

The ERP sufficiency esteems are mapped on the scalp with a shading scale as demonstrated as follows. Blue means negative potential contrasted with standard, red is positive potential compared to baseline and white is no potential compared to baseline. The amplitude is negative when the blue region becomes darker and the amplitude is higher when the red region increases in color. The dark spots on the scalp below represent the amplitude voltage of each position. From this Topo plot view, we can observe the brain activity at each lobes, frontal, parietal, occipital, and temporal. This Topographic Plot view allows us to observe the brain activity from time to time.

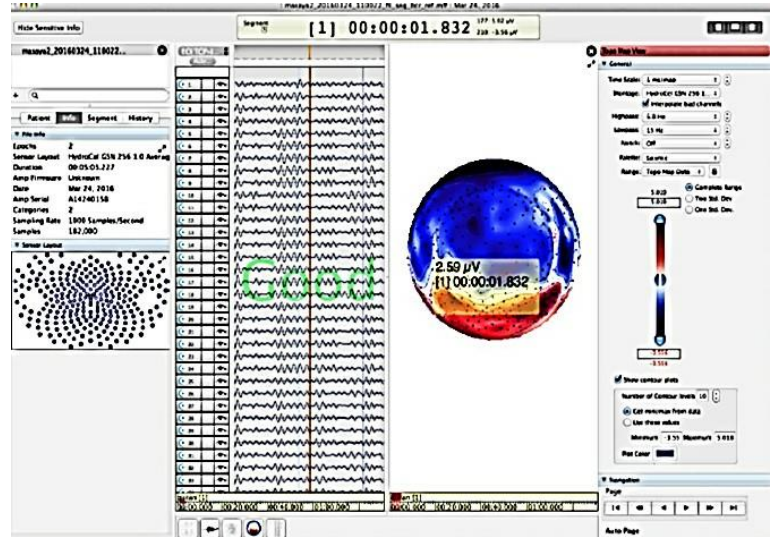

Fig. 6 Topo plot result from Net station view.

Fig. 7 below shows the alpha waves produced from the experiment. Alpha waves indicate that the subject is in a relaxed state of mind for both segments, Quran and Music.

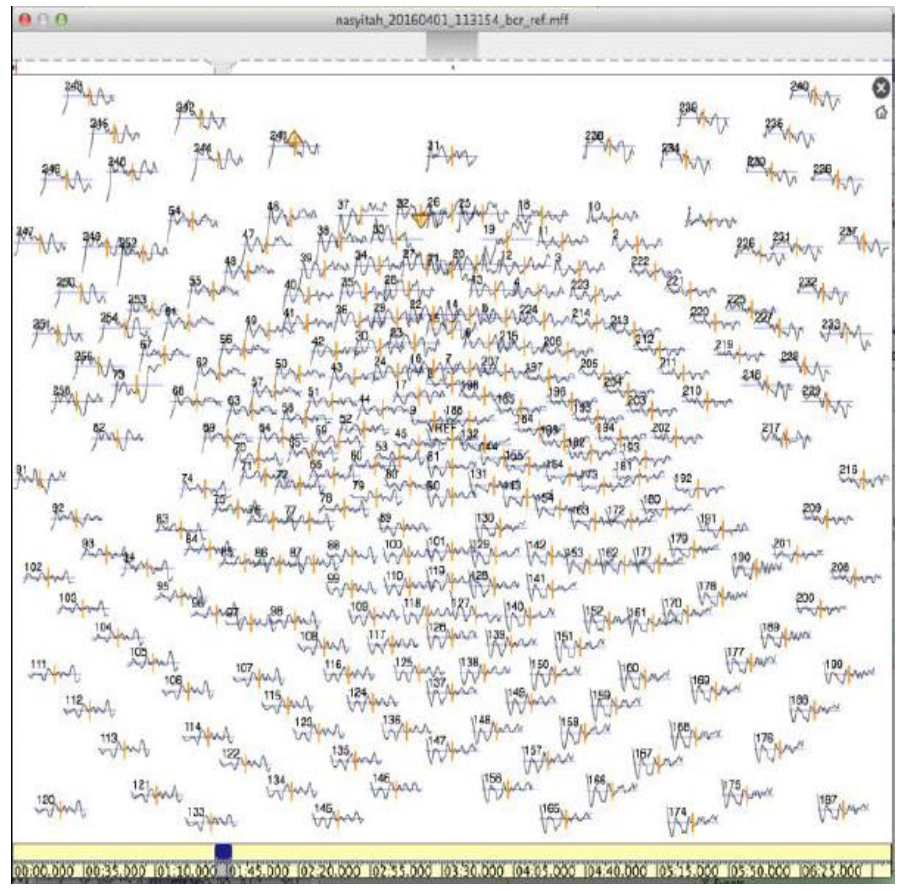

Fig. 7 Brainwaves at each sensor location.

The ERP analysis on Net Station review allows us to observe the alpha brainwaves and the Topographic map at each 256 sensors of electrodes. Both music and Quran recitation has proved that these stimuli can lead the subject to relaxation, which is has also been proved by a previous study. However the aim of this project is to determine which stimulus can lead someone to a higher relaxation state. To differentiate the levels of relaxation between these two stimuli, Power Spectral Density is obtained from these brainwaves. The alpha brainwave power will be calculated by using MATLAB. The EEG data was converted to .mat file by using EGI software. The data was converted to 3D Array, resulting in segmented files consisted of Quran and Music.

\section{Power spectral analysis using MATLAB}

Fig. 8 below shows the data of "Quran", consisting of 257 X 91000 cells in matrix form. 257 cells represent the 256 channel of electrodes +1 ref electrode located at $\mathrm{Cz}$ position. 91000 cells represent the number of samples over time.

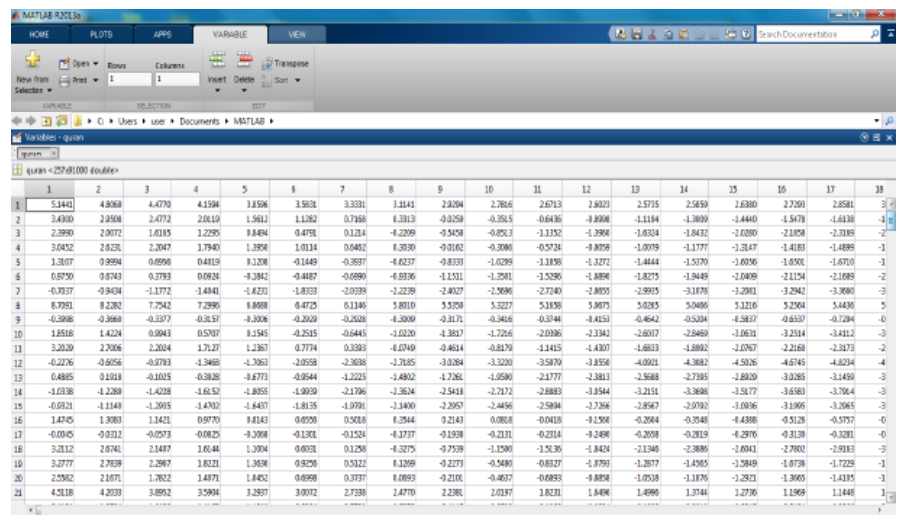

Fig. $83 \mathrm{D}$ array of Quran segment.

Another variable is music, as shown in Fig. 9 below. This variable of segment also has the same number of cell matrix as Quran variable, 257 X 91000 cells.

Throughout these segmented cells, a few electrodes have been chosen in order to determine the alpha power. 14 out of 256 channels were selected to determine the alpha power. These electrodes are, $\mathrm{Pz}$, P1, P2, P3, P4, P5, P6, Poz, Po3, Po4, P9, P10, P07 and Po8. These 
electrodes were chosen because a previous study have proven that $\mathrm{Pz}$, P3 and P4 (according to 10-20 systems) have a higher level of relaxation at these electrodes. After using some code to calculate the brainwaves power, the result of Power Spectral Density is obtained as shown in Fig. 10.

Fig. 10 illustrates the results of brainwaves power. These brainwaves powers are calculated using Welch method. From the result we can see that the alpha power is higher than the rest of the power. The increase in alpha power proves that the subject is in a relaxation state. Data from the 14-channels of Music and Quran are being selected to determine which segment has the higher power.

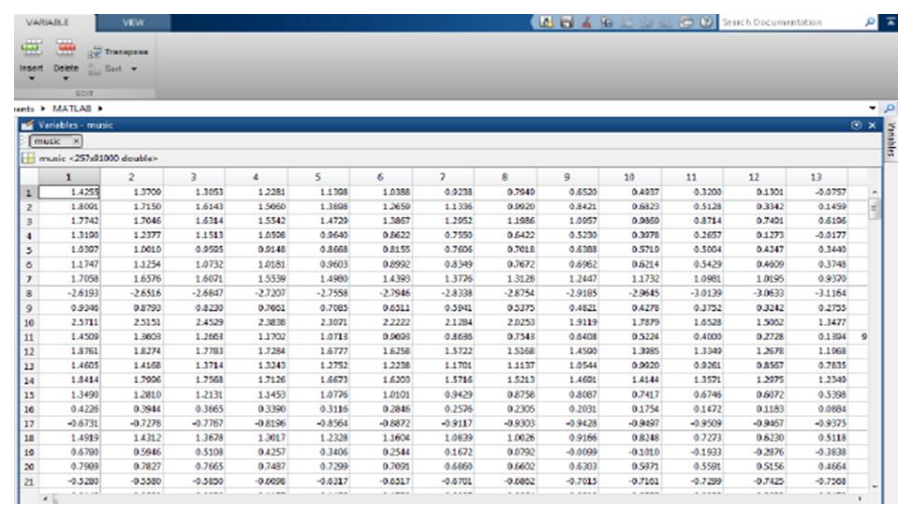

Fig.9 3D array of music segment.

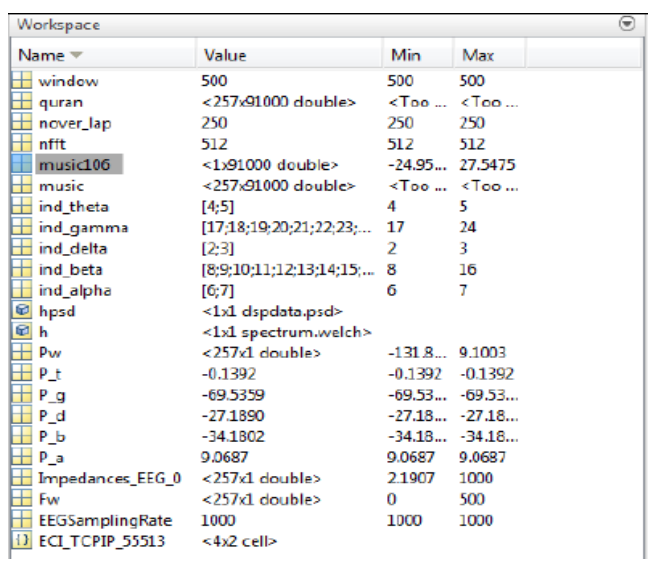

Fig. 10 Power of brainwaves (alpha, beta, delta, gamma, theta).

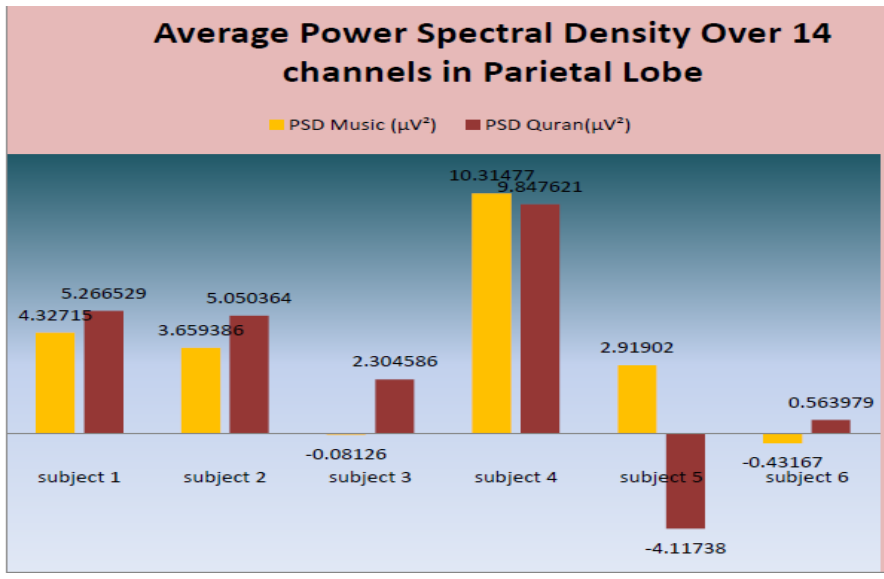

Fig. 11 Summarization of alpha power from the tables for both Quran and music of six subjects.

Fig. 11 above illustrates the Power Spectral Density of alpha brainwave obtained by 14 out of 256 channels of electrodes. These 14 channels are selected from the parietal lobe as a previous study has proved that the parietal lobe attain a higher level of relaxation than any other lobes. From the result, 4 out 6 students tend to have a better relaxation state when they are listening to Quran recitation rather than music.

\section{CONCLUSION}

The result was taken from 14-channels of electrodes in parietal lobe (region of interest). From the result it is clear that four out of six subjects have proven that the alpha power is higher when subject is listening to Quran Recitation compared to music. The increases of alpha power shows that the subjects were in high relaxation state of brain activity. Thus, listening to Quran recitation influences the relaxation of the mind. It was mentioneed in the verse of Quran: "Verily, in the remembrance of Allah do hearts find rest" (Surah ar'Ra'd 13:28). Hence, it can be concluded that the hypothesis of this project correlates with the Quranic verse, and affirms the parallels of science and Quran.

\section{REFERENCES}

Abdullah, A. A., Omar, Z. (2011). The effect of temporal EEG signals while listening to quran recitation. International Journal on Advanced Science, Engineering and Information Technology, 1(4), 372-375.

Amin H.U., Malik A.S., Badruddin N., Chooi WT. (2014). Brain behavior in learning and memory recall process: A high-resolution EEG analysis. In: Goh, J. (eds). The 15th International Conference on Biomedical Engineering. IFMBE Proceedings, 43, Springer, Cham.

Azizi, S. A. (2009). Brain to music to brain! Neuroscience letters, 459(1), 1-2.

Boutros, N.N. (2013). Standard EEG: A research roadmap for neuropsychiatry. USA: Springer.

Cahn, B. R., Polich, J. 2006. Meditation states and traits: EEG, ERP, and neuroimaging studies. Psychological Bulletin, 132 (2), 180.

Chen, A., Zhao, H. (2008). EEG default mode network: Mood modulation (happy-sad) in chinese music (butterfly lovers, violin concerto). International Journal of Psychophysiology, 69 (3), 185.

Davidson, R. J. (1988). EEG measures of cerebral asymmetry: Conceptual and methodological issues. International Journal of Neuroscience, 39, 71-89.

Davidson, R. J., Ekman, P., Saron, C. D., Senulis, J. A., \& Friesen, W. V. (1990). Approach-withdrawal and cerebral asymmetry: Emotional expression and brain physiology: I. Journal of Personality and Social Psychology, 58(2), 330-341.

Davidson, R. J., Hugdahl, K. (2002). The asymmetrical brain. Bradford Books, the MIT Press.

De la Torre-Gea, Guillermo \& Garcia-Manzo, G. (2016). Determination of patterns in the EEG signals during relaxation through music using bayesian networks. International Multispecialty Journal of Health. 2(11), 1 - 7.

Gilman, N. V. (2015). Analysis for science librarians of the 2014 nobel prize in physiology or medicine: The life and work of john o'keefe, edvard moser, and may-britt moser. Science \& Technology Libraries, 34(1), 1-18.

Johnson, G. (1998). Traumatic brain injury survival guide. Retrieved from https://www.google.com/search?q=Traumatic+brain+injury+survival+guide $\% 3 \mathrm{~A} \&$ oq $=$ Traumatic+brain+injury+survival+guide $\% 3 \mathrm{~A} \&$ aqs $=$ chrome..69i5 $7 \mathrm{j} 0.597 \mathrm{j} 0 \mathrm{j} 4 \&$ sourceid $=$ chrome \&ie $=\mathrm{UTF}-8$

Kahn, B. (2005). Electroencephalogram (EEG) signal processing, wave identification, and emotion recognition. California State University, Northridge, United States.

Key, A. P. \& Crowley, M. J. (2012). Introduction to the special issue on EEG/ERP data analysis: Novel approaches for modern data sets. Developmental Neuropsychology, 37(6), 473-475.

McDermott, J. H. (2012). Auditory preferences and aesthetics: Music, voices, and everyday sounds. In R. J. Dolan \& T. Sharot (Eds.), Neuroscience of preference and choice: Cognitive and neural mechanisms (pp. 27-256). San Diego, CA: Elsevier Academic Press.

Sammler, D., Grigutsch, M., Thomas Fritz, T., Koelsch, S. (2007). Music and emotion: electrophysiological correlates of the processing of pleasant and unpleasant music. Psychophysiology,44(2), 293-304.

Schmidt, L. A., \& Trainor, L. J. (2001). Frontal brain electrical activity (EEG) distinguishes valence and intensity of musical emotions. Cognition and Emotion, 15(4), 487-500.

Shekha, M. S., Hassan, A. O., Othman, S. A. (2013). Effects of quran listening and music on electroencephalogram brain waves. The Egyptian Journal of Experimental Biology (Zoology), 9(1), 119-121.

Zhang, H., Hussain, A., Liu, D., Wang, Z. (Eds.). (2012). Advances in brain inspired cognitive systems. 5th International Conference, BICS 2012, Shenyang, China, July 11-14, 2012. Proceedings. Springer.

Trainor, L. (2008). Science \& music: The neural roots of music. Nature, 453, 598-599. 